\title{
Alterações cognitivas em pacientes soropositivos: uma revisão integrativa de
}

\section{literatura}

\author{
Cognitive changes in HIV-positive patients: an integrative literature review \\ Cambios cognitivos en pacientes VIH positivos: una revisión integradora de la literatura
}

Recebido: 06/11/2021 | Revisado: 15/11/2021 | Aceito: 15/11/2021 | Publicado: 24/11/2021

Letícia Beatriz Rodrigues Bernardes
ORCID: https://orcid.org/0000-0001-5760-214X
Centro Universitário de Patos de Minas, Brasil
E-mail: leticiabernardes@ unipam.edu.br
Bárbara Queiroz de Figueiredo
ORCID: https://orcid.org/0000-0003-1630-4597
Centro Universitário de Patos de Minas, Brasil
E-mail: barbarafigueiredo@ unipam.edu.br
Danilo Lima Fraga Amorim
ORCID: https://orcid.org/0000-0001-8815-9881
Centro Universitário de Goiatuba, Brasil
E-mail: danilolfa22@gmail.com
Gabriela Inácio Sartório
ORCID: https://orcid.org/0000-0001-6719-4290
Centro Universitário de Goiatuba, Brasil
E-mail: gabii_sartorio@ hotmail.com
Lunalva Gabrielli Veras Sousa
ORCID: https://orcid.org/0000-0001-5181-5371
Centro Universitário Uninovafapi, Brasil
E-mail: veraslunalva@gmail.com
Marcelo Gomes de Almeida
ORCID: https://orcid.org/0000-0002-6297-4383
Universidade Federal de Minas Gerais, Brasil
E-mail: marcelomedile@yahoo.com.br

\begin{abstract}
Resumo
Introdução: A síndrome da imunodeficiência adquirida (AIDS) é causada pelo vírus da imunodeficiência humana (HIV), que ataca o sistema imunológico e pode reduzir a capacidade de uma pessoa infectada de resistir a outras infecções e doenças. Estima-se que mais de 50\% dos indivíduos afetados com HIV são suscetíveis a desenvolver declínio neurocognitivo associado ao HIV. Objetivo: explorar, por meio de revisão integrativa de literatura, as alterações estruturais cerebrais e declínio cognitivo em pacientes portadores de HIV. Metodologia de busca: trata-se de uma pesquisa descritiva do tipo revisão narrativa da literatura, através do acesso online nas bases de dados PubMed, Scielo, CDSR, Google Scholar, BVS e EBSCO, no mês de setembro de 2021. Discussão: a AIDS pode manifestar-se como uma demência subcortical, que se manifesta como uma perda significativa na capacidade de atenção e concentração, sintomas depressivos e alterações motoras em relação à velocidade e precisão de realizar diferentes tarefas. Essa síndrome é associada com alterações patológicas no cérebro que incluem atrofia generalizada, mudanças na substância branca causando leucoencefalopatia, nódulos microgliais típicos de encefalite viral e as células gigantes multinucleadas, que parecem ser diretamente infectadas pelo HIV. Considerações finais: embora o vírus HIV seja reconhecido pelo seu efeito direto no sistema imune celular através da depleção de linfócitos T CD4, o vírus também é associado ainda a amplos efeitos sobre o sistema nervoso, incluindo efeito direto no cérebro, medula espinal e nervos periféricos.
\end{abstract}

Palavras-chave: HIV; Declínio cognitivo; Macrófagos; Barreira hematoencefálica.

\begin{abstract}
Introduction: Acquired immunodeficiency syndrome (AIDS) is caused by the human immunodeficiency virus (HIV), which attacks the immune system and can reduce an infected person's ability to resist other infections and diseases. It is estimated that more than $50 \%$ of individuals affected with HIV are susceptible to developing HIV-associated neurocognitive decline. Objective: to explore, through an integrative literature review, the structural changes in the brain and cognitive decline in HIV patients. Search methodology: this is a descriptive research of the narrative literature review type, through online access in the PubMed, Scielo, CDSR, Google Scholar, BVS and EBSCO databases, in September 2021. Discussion: AIDS it can manifest as a subcortical dementia, which manifests itself as a significant loss in the capacity for attention and concentration, depressive symptoms and motor alterations in relation
\end{abstract}


to the speed and precision of performing different tasks. This syndrome is associated with pathological changes in the brain that include generalized atrophy, white matter changes causing leukoencephalopathy, microglial nodules typical of viral encephalitis, and multinucleated giant cells, which appear to be directly infected with HIV. Final considerations: although the HIV virus is recognized for its direct effect on the cellular immune system through the depletion of CD4 T lymphocytes, the virus is also still associated with broad effects on the nervous system, including a direct effect on the brain, spinal cord and peripheral nerves.

Keywords: HIV; Cognitive decline; Macrophages; Blood-brain barrier.

\section{Resumen}

Introducción: El síndrome de inmunodeficiencia adquirida (SIDA) es causado por el virus de la inmunodeficiencia humana (VIH), que ataca el sistema inmunológico y puede reducir la capacidad de una persona infectada para resistir otras infecciones y enfermedades. Se estima que más del $50 \%$ de las personas afectadas por el VIH son susceptibles de desarrollar un deterioro neurocognitivo asociado al VIH. Objetivo: explorar, a través de una revisión integradora de la literatura, los cambios estructurales en el cerebro y el deterioro cognitivo en pacientes con VIH. Metodología de búsqueda: se trata de una investigación descriptiva del tipo revisión de literatura narrativa, mediante acceso online en las bases de datos PubMed, Scielo, CDSR, Google Scholar, BVS y EBSCO, en septiembre de 2021. Discusión: El SIDA puede manifestarse como una demencia subcortical, que se manifiesta como una pérdida significativa en la capacidad de atención y concentración, síntomas depresivos y alteraciones motoras en relación a la rapidez y precisión en la realización de diferentes tareas. Este síndrome se asocia con cambios patológicos en el cerebro que incluyen atrofia generalizada, cambios en la sustancia blanca que causan leucoencefalopatía, nódulos microgliales típicos de encefalitis viral y células gigantes multinucleadas, que parecen estar directamente infectadas por el VIH. Consideraciones finales: aunque el virus del VIH es reconocido por su efecto directo sobre el sistema inmunológico celular a través del agotamiento de los linfocitos T CD4, el virus todavía está asociado con amplios efectos sobre el sistema nervioso, incluido un efecto directo sobre el cerebro y la médula espinal. y nervios periféricos.

Palabras clave: VIH; Deterioro cognitivo; Macrófagos; Barrera hematoencefálica.

\section{Introdução}

A síndrome da imunodeficiência adquirida (AIDS) é um dos problemas de saúde mais sérios e complexos que a humanidade enfrentou na história recente, e é causada pelo vírus da imunodeficiência humana (HIV), que ataca o sistema imunológico e pode reduzir a capacidade de uma pessoa infectada de resistir a outras infecções e doenças (Yadav et al. 2017). Estima-se que mais de $50 \%$ dos indivíduos afetados com HIV são suscetíveis a desenvolver declínio neurocognitivo associado ao HIV (Heaton et al. 2015), haja vista que o vírus é capaz de cruzar a barreira hematoencefálica em um estágio inicial durante a infecção, estabelecendo um meio inflamatório que causa danos às conexões sinaptodendríticas, resultando, assim, em disfunção neuronal (Thomas et al. 2013).

Sob esse cenário, essas mudanças no nível neuronal podem ocorrer muito mais cedo do que os sintomas cognitivos em um indivíduo não infectado pelo vírus, (Holt et al. 2012). Mesmo com uma expectativa de vida aumentada devido aos avanços terapêuticos no tratamento de indivíduos soropositivos, os déficits neurocognitivos geralmente os afetam de maneira precoce (Thomas et al. 2013). Aliado a isso, segundo Ragin et al. (2012), pacientes pediátricos com HIV apresentaram atraso no desenvolvimento neurológico e, posteriormente, comprometimento cognitivo, incluindo deficiências visuais, de linguagem, atenção, memória, aprendizagem e audição. Desse modo, a neuroimagem pode servir como uma ferramenta potencial para fornecer percepções quantitativas sobre a progressão do declínio cognitivo nestes indivíduos, como espectroscopia de ressonância magnética, volumetria, imagem por tensor de difusão e PET (Holt et al. 2012). Segundo estudo de Masters et al. (2014), ao utilizar técnicas quantitativas de ressonância magnética, foi demonstrado afinamento da substância cinzenta cortical e interrupção específica da integridade da substância branca no cérebro, em indivíduos com HIV.

Ademais, foi demonstrado, em estudo de Ortega et al. (2015) que a conectividade entre as redes corticoestriatais é afetada em indivíduos portadores de AIDS, no entanto, essas alterações não foram correlacionadas com contagens de células T CD4 , cargas virais plasmáticas ou escores de avaliação neurológica. Além disso, mudanças nas características da rede cerebral durante o curso da infecção pelo HIV também foram exploradas usando magnetoencefalografia (Wilson et al. 2015). Ou seja, embora esforços tenham sido feitos empregando diferentes técnicas, métodos mais novos são necessários para desenvolver 
uma melhor compreensão da fisiopatologia do declínio cognitivo em pacientes soropositivos (Saylor et al. 2016). Assim, dada a alta probabilidade da ocorrência deste evento em longo prazo, há uma demanda crescente por biomarcadores que tenham o potencial de melhorar a detecção de lesão do sistema nervoso central. Portanto, dadas as circunstâncias, o objetivo do presente estudo pauta-se em explorar, por meio de revisão integrativa de literatura, as alterações estruturais cerebrais e declínio cognitivo em pacientes portadores de HIV.

\section{Metodologia}

Trata-se de uma pesquisa descritiva do tipo revisão narrativa da literatura, que buscou responder quais são as evidências sobre as alterações estruturais cerebrais e declínio cognitivo em pacientes portadores de HIV. A pesquisa foi realizada através do acesso online nas bases de dados National Library of Medicine (PubMed MEDLINE), Scientific Electronic Library Online (Scielo), Cochrane Database of Systematic Reviews (CDSR), Google Scholar, Biblioteca Virtual em Saúde (BVS) e EBSCO Information Services, no mês de setembro de 2021.

Para a busca das obras foram utilizadas as palavras-chaves presentes nos descritores em Ciências da Saúde (DeCS): em inglês: "HAART; HIV; Cognitive Dysfunction; Dementia; AIDS Dementia Complex; Cognition; Blood-Brain Barrier; Neuropsychological Tests; CNS", em espanhol: "TARGA; VIH; disfunción cognitiva; demencia; complejo de demencia del SIDA; cognición; barrera hematoencefálica; pruebas neuropsicológicas y sistema nervioso central" e em português: "HAART; HIV; Disfunção Cognitiva; Demência; Complexo AIDS demência; Cognição; Barreira Hematoencefálica; Testes neuropsicológicos; SNC".

Como critérios de inclusão, foram considerados artigos originais, que abordassem o tema pesquisado e permitissem acesso integral ao conteúdo do estudo, publicados no período de 2009 a 2021, em inglês e português. O critério de exclusão foi imposto naqueles trabalhos que não estavam em inglês e espanhol, que não tinham passado por processo de Peer-View e que não abordassem a temática do estudo. A estratégia de seleção dos artigos seguiu as seguintes etapas: busca nas bases de dados selecionadas; leitura dos títulos de todos os artigos encontrados e exclusão daqueles que não abordavam o assunto; leitura crítica dos resumos dos artigos e leitura na íntegra dos artigos selecionados nas etapas anteriores. Assim, totalizaram-se 21 artigos científicos para a revisão integrativa da literatura, com os descritores apresentados acima, dos últimos doze anos e em línguas portuguesa e inglesa.

\section{Resultados e Discussão}

\subsection{HIV e infecção do Sistema Nervoso Central}

$\mathrm{O}$ vírus da Imunodeficiência Adquirida apresenta dois subtipos conhecidos como HIV-1 e HIV-2 que, embora tenham as mesmas vias de transmissão, de infecção permanente da célula e a capacidade de desencadear a Síndrome da Imunodeficiência Adquirida (SIDA), apresentam distinções em relação à carga viral e ao tempo de evolução da infecção (Heaton et al., 2015). Tais diferenças possuem significado relevante para os quadros de declínio cognitivo em pacientes soropositivos, haja vista que, de acordo com Antunes (2017), o HIV-1 é o subtipo que apresenta maior virulência e evolução mais célere e por isso possui maior relação com possíveis alterações cognitivas. Assim como o HIV-2, o HIV-1 também apresenta como alvo principal os linfócitos CD4+, no entanto outras células também são acometidas por esse vírus, como a linhagem monócito- macrófago (Holt et al., 2012). O mecanismo invasivo do vírus HIV se deve a algumas características que as células infectadas por ele possuem em comum, a exemplo dos receptores na membrana celular, como o CXCR4 e o CCR5 (Kalil et al., 2009).

No Sistema Nervoso Central (SNC), a presença da Barreira Hematoencefálica (estrutura que impede a passagem de substâncias, partículas ou microrganismos nocivos presentes no sangue para o tecido nervoso) não é suficiente para evitar a 
entrada do vírus HIV (Saylor et al., 2016). A explicação para esse fato consiste em um mecanismo pautado na atuação da linhagem monócito-macrófago e que é denominado "Cavalo de Tróia” (Antunes, 2017). Os monócitos são células capazes de atravessar sem empecilho a Barreira Hematoencefálica. Dessa forma, linhagens de monócitos infectadas pelo vírus transpassam a BHE por diapedese e uma vez no SNC se diferem em macrófagos (Masters et al., 2014).

Os macrófagos podem desencadear nesse sistema uma produção elevada de citocinas e propiciar um quadro neuro inflamatório que, por sua vez, pode ocasionar a morte de células nervosas, como os neurônios (Thomas et al., 2013). Ademais, a produção de proteínas virais possui potencial para incorrer em prejuízo direto para o funcionamento correto do SNC, haja vista que elas têm capacidade de danificar o binômio dendrito-sinapse. Essa possibilidade do vírus se instalar no SNC incorre em efeitos ainda mais catastróficos para o organismo de modo geral, isso porque segundo Baldez (2011):

"Vários fatores, como as características imunitárias específicas do SNC, a BHE, a rápida mutação e recombinação do HIV-1 e a dificuldade de penetração de fármacos antirretrovirais através da BHE contribuem para a compartimentação viral no SNC, criando assim um reservatório que permite a replicação do HIV-1 independente da periferia."

O declínio cognitivo devido à infecção pelo HIV também pode se dar de maneira indireta, isto é, por meio da imunossupressão (Wilson et al., 2015). O sistema imunológico debilitado pode permitir o desenvolvimento de doenças infecciosas oportunistas como a neurocriptococose, neurotoxoplasmose e a leucoencefalopatia multifocal progressiva (Duarte et al, 2019), conforme ilustrado pelo Fluxograma 1.

Fluxograma 1: Mecanismos para o declínio cognitivo em pacientes soropositivos.

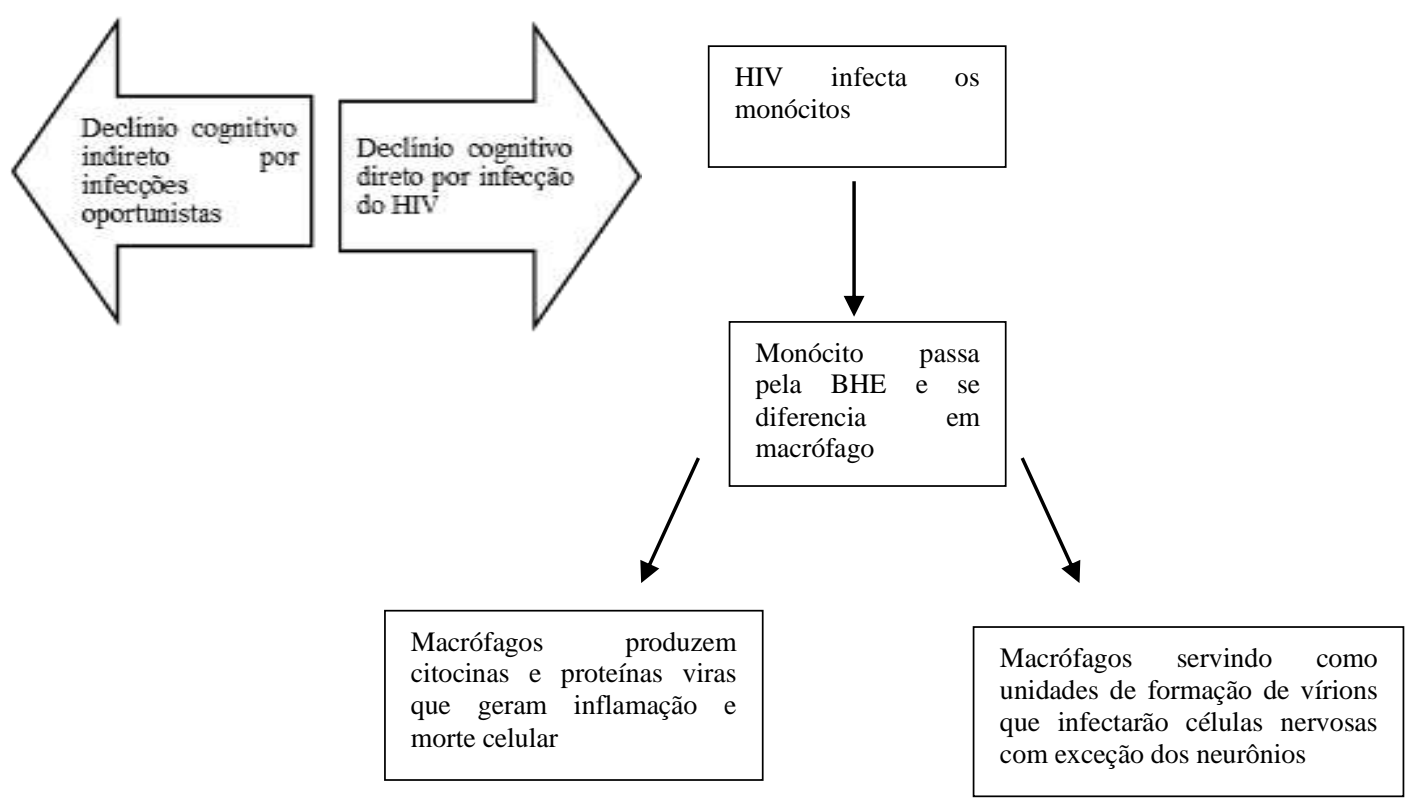

Fonte: Autores (2021).

\section{2 Áreas do SNC afetadas pelo HIV}

As funções cognitivas consistem em um conjunto de habilidades (percepção, linguagem, memória, atenção que não podem ser observadas diretamente, mas que é possível inferir pelo comportamento (Kalil et al., 2009). A infecção do SNC pelo vírus HIV pode acometer áreas especiais relacionadas com a cognição, desencadeando assim declínio cognitivo e até mesmo demência. As áreas mais comumente acometidas pelo vírus são o hipocampo, regiões neocorticais e gânglios da base. 


\section{- Hipocampo}

O hipocampo consiste em uma área do encéfalo situada acima do giro para-hipocampal e é constituído de um córtex antigo denominado arquicórtex. Essa área um dos constituintes da formação hipocampal e faz parte do sistema límbico (sistema que contempla diversas estruturas encefálicas e tem como função motivação, aprendizado, emoções e memória) (Ragin et al., 2012). A infecção pelo vírus HIV tem potencial para desencadear lesões no hipocampo, dado a neurotoxicidade do vírus. Tais lesões se manifestam clinicamente como perda de memória anterógrada (Kalil et al., 2009).

\section{- Neocórtex}

Consiste em uma das partes corticais do telencéfalo. Possui seis camadas de neurônios e axônios que se repetem em todo a extensão do neocórtex, formando um circuito denominado microcircuito cortical canônico. É dividido em 3 regiões, quais sejam, sensorial, motora e a associativa que se correlacionam com funções cognitivas complexas (Shimoura, 2021). Os danos provocados pelo HIV nessa área podem desencadear perda de atenção e distúrbios na linguagem.

\section{- Gânglios da base}

Consiste em grupo de núcleos (núcleo caudado, putâmen, globo pálido, substância nigra e núcleo subtalâmico) constituídos por substância cinzenta e que se conectam formando o sistema extrapiramidal. As lesões nesse núcleo produzem principalente danos motores, porém também se observam problemas cognitivos (Tumas, 2016).

\subsection{Fatores de Risco para declínio cognitivo associados ao HIV}

O declínio cognitivo relacionado à infecção pelo HIV pode também estar associado a fatores de risco, isto é, fatores que podem potencializar os danos ocasionados pela infecção do HIV no SNC.

\section{- Genética}

As características genéticas dos indivíduos são significativas para a patogênese viral. Nesse contexto, indivíduos que apresentam mutação no gene CCR5 são menos propensos a danos cognitivos ocasionados pelo HIV (Antunes, 2017). Isso é reflexo da menor produção do receptor CCR5 que está presente especialmente na linhagem monócito-macrófago que é essencial para o mecanismo de "cavalo de troia" (Yadav et al., 2017).

- Infecção concomitante pelo vírus da hepatite $\mathrm{C}(\mathrm{HCV})$

O vírus da hepatite c também tem a capacidade de provocar danos cognitivos. Quando associados ao HIV, a probabilidade de que distúrbios cognitivos ocorram pode duplicar (Baldez, 2011).

\section{- $\quad$ Níveis de CD4+}

As CD4+ são células imunes que preferencialmente são atacadas pelo vírus HIV. Quanto menor os níveis de CD4+, mais comprometido fica o sistema imunológico e, consequentemente, maiores são os riscos das complicações da infecção ocasionada pelo HIV. Dessa forma, os danos cognitivos são mais propensos de acontecer em indivíduos com menores níveis de CD4+ (Valença, 2021), conforme ilustrado pela Tabela 1. 
Tabela 1: Níveis de CD4+ e risco de declínio cognitivo.

\begin{tabular}{c|c}
\hline Níveis de CD4+ & Risco de declínio cognitivo \\
\hline$>349$ cels $/ \mathrm{mm} 3$ & Alto risco \\
\hline $200-349$ cels $/ \mathrm{mm} 3$ & Médio risco \\
\hline$<200$ cels $/ \mathrm{mm} 3$ & Baixo risco \\
\hline
\end{tabular}

Fonte: Baldez (2011).

- Abuso de drogas

Drogas psicoativas tem a capacidade de desencadear alterações neurocognitivas em seus usuários independente de possuírem ou não algum tipo de patologia. Isso se deve porque essas substâncias podem propiciar a morte de células nervosas, promover vasoconstrição e alteração na arquitetura cerebral (Silva, 2018). Em pacientes HIV positivo tais alterações podem ser ainda mais patentes, haja vista que as drogas podem fomentar condições para maior replicação viral bem como para uma depressão do sistema imune (Cordeiro, 2019).

- Idade avançada

O vírus HIV, uma vez instalado no SNC, pode acarretar danos tanto nas células nervosas quanto nas sinapses. Esses danos tem a capacidade de facilitar manifestações clínicas das doenças neurodegenerativas (Baldez, 2011).

\subsection{Manifestações clínicas}

A infecção do SNC pelo vírus HIV pode causar diversos problemas como os transtornos neurocognitivos associados ao HIV (HAND). Esses transtornos, de acordo com Antunes (2017), podem ainda ser classificados como comprometimento neurocognitivo assintomático (ANI), comprometimento neurocognitivo ligeiro associado ao HIV (MND) e demência associada ao HIV (HAD).

- Comprometimento neurocognitivo assintomático (ANI) e comprometimento neurocognitivo ligeiro associado ao HIV (MND)

O ANI é um tipo de transtorno que não causa impactos nas atividades de vida diária, bem como não encontra similaridades com delirium e nem demência. Sua detecção é feita por meio de avaliações que levam em consideração diversas funções cognitivas como a atenção, memória, velocidade de processamento e linguagem (Ortega et al., 2015). Geralmente não coexiste nenhuma outra possível causa para o déficit cognitivo e há ao menos um comprometimento de uma das funções cognitivas (Christo, 2010). No MND, assim como no ANI, não há similaridade com demência e nem delirium, porém nesse tipo de transtorno há interferência nas atividades de vida diária de modo que pode haver uma ineficiência no trabalho e perturbações no funcionamento social (Christo, 2010).

\section{- Demência associada ao HIV (HAD)}

A HAD é um tipo de transtorno que causa impactos significativos nas atividades de vida diária. Sua manifestação é usualmente tardia e compromete dois ou mais domínios cognitivos (Antunes, 2017). As manifestações clínicas mais evidentes são as alterações motora (visível alteração de marcha, descoordenação dos membros e até mesmo fraqueza) sociocomportamental (atitudes impróprias e desinibição) e emocional (irritabilidade e apatia) (Christo, 2010). A HAD pode ocorrer isolada ou associada a outros transtornos cognitivos; o que não é observado nem no ANI e nem no MND. A HAD apresenta particularidades que permitem diferenciá-la de outros tipos de demências, como explicita Antunes (2017): 
"Os pacientes com HAD apresentam com alguma frequência um comprometimento das habilidades motoras, mesmo quando as funções cognitivas permanecem relativamente preservadas. As manifestações motoras de HAD incluem: lentificação psicomotora, marcha instável, perda de equilíbrio, falta de coordenação, tremores e comprometimento de habilidades motoras finas (como a caligrafia). A presença de disfunção motora associada a alterações cognitivas é o principal fator que permite distinguir a HAD de outras demências."

\subsection{Avaliação das alterações cognitivas causadas pelo HIV}

O declínio cognitivo em pacientes HIV positivo pode se manifestar como alterações cognitivas leves como também pode se apresentar de maneira grave a exemplo da demência associada ao HIV (HAD) (Christo, 2010). Dado esse fato, os testes neuropsicológicos para a avaliação das alterações cognitivas são múltiplos. Os principais testes utilizados são Baterias de Prova de Raciocínio (BPR5), Teste de Inteligência Não Verbal, Figuras complexas de Rey, Escala de Inteligência Wechsler para Adulto, Teste Bender-Guestáltico e Matrizes Progressivas Coloridas de Raven, conforme elucidado no Quadro 1.

Quadro 1: Testes neuropsicológicos para avaliação de pacientes soropositivos.

\begin{tabular}{|c|c|}
\hline $\begin{array}{l}\text { Baterias de Prova de Raciocínio } \\
\text { (BPR5) }\end{array}$ & Avaliação do raciocínio verbal, abstrato, espacial, numérico e mecânico \\
\hline $\begin{array}{l}\text { Teste de Inteligência Não } \\
\text { Verbal }\end{array}$ & Identifica os tipos de raciocínios errados e como eles são executados \\
\hline Figuras complexas de Rey & Averigua a memória e a organização viso-espacial \\
\hline $\begin{array}{l}\text { Escala de Inteligência Wechsler } \\
\text { para adulto }\end{array}$ & $\begin{array}{l}\text { Avalia a velocidade de processamento, compreensão verbal, memória de } \\
\text { trabalho e organização perceptual }\end{array}$ \\
\hline Teste Bender-Guestáltico & Mensurar inteligência e identificar danos orgânicos cerebrais \\
\hline $\begin{array}{l}\text { Matrizes Progressivas Coloridas } \\
\text { de Raven }\end{array}$ & Avalia a inteligência e a capacidade abstrativa \\
\hline $\begin{array}{l}\text { Teste Neuropsicológico } \\
\text { Computadorizado }\end{array}$ & Avaliação de atenção \\
\hline
\end{tabular}

Fonte: Christo (2010).

\subsection{Tratamento}

Identificada em humanos pela primeira vez em 1981, a SIDA (como era chamada anteriormente), acarretou a morte de milhões de pessoas, haja vista que esta síndrome causada pelo HIV tem capacidade de comprometer o funcionamento do sistema imunológico deixando o organismo susceptível a infecções oportunistas como a tuberculose, candidíase esofágica e pneumonia. Dado esse fato, foi um grande desafio para a comunidade global conter essa doença bem como instituir um tratamento (Mahmud et al., 2020).

Durante a década de 1990, surgiu a terapia antirretroviral altamente ativa (HAART), que impede a replicação viral e consequentemente também melhora a infecção imunológica, haja vista que reduz a infecção tanto das CD4+ quanto das CD8+. No entanto, a cura não foi obtida com essa terapia, ocasionando uma infecção crônica, porém com menores taxas de mortalidade (Silva, 2015). Apesar desse avanço, os estigmas relacionados ao HIV ainda são patentes, causando sofrimento psíquico para os pacientes portadores dessa doença. No que tange aos HAND, a HAART impede o desenvolvimento da demência associada ao HIV, porém não consegue impedir os distúrbios neurocognitivos menores como o ANI e o MND que têm aumentado significativamente (Silvany, 2011).

\section{Conclusão}

Desse modo, perante os achados deste estudo, nota-se que, provavelmente, mais da metade dos pacientes que vivem com HIV desenvolverão algum grau de perda cognitiva associada especificamente ao vírus, e, embora a deficiência neurocognitiva grave e progressiva tenha se tornado rara em pacientes com HIV na era da terapia antirretroviral, a maioria 
desses pacientes apresentam alterações em testes neurocognitivos formais. Esses sintomas são causados por uma variedade de desordens de forma que diagnósticos específicos podem ser difíceis.

Embora o vírus HIV seja reconhecido pelo seu efeito direto no sistema imune celular através da depleção de linfócitos T CD4, o vírus HIV é associado ainda a amplos efeitos sobre o sistema nervoso, incluindo efeito direto no cérebro, medula espinal e nervos periféricos. Demência primária associada ao vírus da imunodeficiência humana, combinada com infecções oportunistas e de doenças malignas, constitui as chamadas manifestações neurológicas do HIV.

\section{Referências}

Antunes, F. A. M. (2017). HIV e o sistema nervoso central: mecanismos de invasão e patogênese. Mestrado Integrado de Ciências Farmacêuticas: Universidade de Lisboa, 1-86.

Baldez, R. A. R. (2011). Estudo da prevalência das alterações cognitivas ligadas ao HIV em pacientes portadores da infecção pelo HIV/AIDS. Mestrado em Pesquisa Clínica em Doenças Infecciosas: Fundação Oswaldo Cruz, 1-87.

Christo, P. P. (2010). Alterações cognitivas na infecção pelo HIV e Aids. Revista da Associação Médica Brasileira, 56 (2), $242-247$.

Cordeiro, M. S. M. (2019). Distúrbios neurocognitivos associados à infecção por HIV: patogênese e perspectivas de tratamento. Mestrado Integrado em Ciências Farmacêuticas: Universidade de Lisboa, 1-38.

Duarte, E. A. C., et al. (2019). Avaliação intra-hospitalar da prevalência de alterações cognitivas em pacientes HIV positivos e fatores associados. Dissertação: Universidade do Sul da Catarina, 1-48.

Hearton, R. L., et al. (2015). Mudança neurocognitive na era da terapia antirretroviral combinada para o HIV: o estudo longitudinal CHARTER. Clin Infectar Dis., 60 (4), 473-480.

Holt, J. L., et al. (2012). Estudos de neuroimagem do cérebro infectado com HIV-1 em envelhecimento. J. Neurovirol., 18 (6), $291-302$.

Kalil, R. S., et al. (2009). Estudo dos transtornos cognitivos decorrentes da infecção pelo HIV-1. Estudos de Psicologia, 26 (4), $465-473$.

Mahmud, I. C., et al. (2020). Transtornos cognitivos em idosos vivendo com HIV: uma revisão dos fatores de risco e mecanismos patogênicos. Temas em Saúde, 20 (1), 403-416.

Masters, M. C., et al. (2014). Papel da neuroimagem em distúrbios neurocognitivos associados ao HIV. Semin Neurol., 34 (1), 89-102.

Ortega, M., et al. (2015). Efeitos do HIV e da terapia antirretroviral combinada na conectividade funcional corticoestriatal. AIDS, 29 (3), 703-712.

Ragin, A. B., et al. (2012). Alterações estruturais do cérebro podem ser detectadas no início da infecção pelo HIV. Neurology, 79 (24), $2328-2334$.

Saylor, D., et al. (2016). Transtorno neurocognitivo associado ao HIV - patogênese e perspectivas de tratamento. Nat. Rev. Neurol., 12 (4), $232-234$.

Shimoura, R. O., et al. (2021). Modelos de redes de neurônios para o neocórtex e fenômenos emergentes observados. Revista Brasileira de Ensino e Física, 43 (1), 1-12.

Silva, A. K. B. L. (2018). Alterações no sistema nervoso ocasionadas pelo HIV - AIDS. Trabalho de Conclusão de Curso: Centro Universitário de Brasília, 116.

Silva, D. V. (2015). HIV/Drogas: o imperativo da adesão a HAART e papel da educação em saúde nesta modelagem. Mestrado em Pesquisa Clínica em Doenças Infecciosas: Fundação Oswaldo Cruz, 1-126.

Silvany, S. M. (2011). Prevalência e fatores associados às alterações neurocognitivas em pacientes infectados com HIV-1/aids. Dissertação de Mestrado: Universidade de São Paulo, 1-81.

Thomas, J. B., et al. (2013). Caminhos para os efeitos da neurodegeneração do HIV e do envelhecimento na conectividade funcional em estado de repouso. Neurology, 80 (8), 1186-1193.

Valença, M. M. (2021). Alterações cognitivas em pacientes com HIV-AIDS. Avanços em Medicina, 1 (1), 79-88.

Wilsin, T. W., et al. (2015). Evidência de neuroimagem multimodal de alterações na estrutura e função cortical em idosos infectados pelo HIV. Zumbir. Brain Mapp., 36 (5), 897-910.

Yadav, K. S., et al. (2017). Alterações estruturais do cérebro e desempenho neurocognitivo em HIV pediátrico. Neuroimage, 14 (3), $316-322$. 